\title{
Increased expression of cardiac IL-17 after burn
}

\author{
Richard F Oppeltz, Qiong Zhang, Meenakshi Rani, Jennifer R Sasaki, Martin G Schwacha*
}

\begin{abstract}
Background: Cardiac dysfunction is a common complication associated with major burns. While recent findings have linked the Th-17 T-cell response to the development of autoimmune myocarditis, the role of IL-17 and the Th-17 T-cell response in the development of post-burn cardiac dysfunction remains unknown.

Methods: Male C57BL/6 mice were subjected to a major burn ( $3^{\text {rd }}$ degree, 25\% TBSA) or sham treatment. Three hours after injury plasma and tissue (i.e., heart, lung, liver, small intestine) samples were collected and analyzed for the expression of Th-17 cytokine (i.e., IL-6, IL-17, IL-22, IL-23, TGF- $\beta$ ) levels by ELISA.

Results: Cardiac tissue levels of the Th-17 cytokines, IL-6, IL-17 and IL-22 were significantly elevated at 3 hrs after burn as compared to sham levels. IL-17 was analyzed 1, 3 and 7 days after burn and showed a return to baseline levels and without a difference in the burn group. Burn-induced alterations in the level of these cytokines in plasma or other tissues were not evident. The cardiac Th-17 cytokine response after burn injury was specific, as cardiac levels of Th-1 (IFN- $\gamma$ ) and Th-2 (IL-10) cytokines were not significantly affected after injury. The cardiac Th-17 response correlated with a significant increase in Troponin levels at $3 \mathrm{hr}$. after burn.
\end{abstract}

Conclusion: These findings indicate that early after burn, cardiac tissue is associated with significantly elevated levels of Th-17 cytokines. The early Th-17 response after burn appears to be specific for cardiac tissue and may promote myocardial inflammation and dysfunction associated with this form of trauma.

\section{Background}

Burn injury initiates changes in the immune function that result in local and systemic inflammation that can lead to life-threatening end-organ dysfunction. Cardiac dysfunction after burn has been well described and has been shown to play an important role in patient outcome [1]. Several studies have been conducted to explain the pathways involved in myocardial dysfunction after burn since the early studies of Blalock in the 1930's [2]. Excessive production of pro-inflammatory cytokines, interleukin (IL)-6 IL-1 $\beta$ and tumor necrosis factor- $\alpha$ (TNF- $\alpha$ ) have been associated with the cardiac cell damage [3]. Studies have shown differences in the cytokine expression profile in severely burned patients and in the magnitude of the systemic and compartmental inflammatory response correlated with progressive left ventricular contraction and relaxation defects, achieving a nadir with $40 \%$ of TBSA burn $[3,4]$. While studies have implicated cardiomyocytes as a cellular source of pro-inflammatory cytokines after burn, other cell populations are also clearly important $[5,6]$.

Recently a novel class of T-helper cells, called Th-17 cells, has been found to secrete the pro-inflammatory cytokine IL-17 [7]. This recently discovered cytokine appears to play an important role in inflammation and autoimmunity. Moreover, in addition to IL-17, other cytokines such as IL- 6 and TGF- $\beta$, normally associated with inflammation, are also associated with Th-17 cells. In this regard, the Th-17 response has been recently implicated in the response to several models of infection [8]. This suggests that the Th-17 response may be important in the inflammatory response after burn.

The importance of cardiomyocyte injury after burn has been emphasized in recent years, however, its pathogenesis, has not been fully clarified. In the current study we examined the role of the Th-17 mediated inflammatory response in the development of the cardiac injury after burn in a mouse model.

\footnotetext{
* Correspondence: schwacha@uthscsa.edu

Department of Surgery, The University of Texas Health Science Center, San Antonio, TX, 78229, USA
} 


\section{Methods}

Animals

C57BL/ 6 male mice (18 to 22 g; 8 to 10 wk of age, Charles River Laboratories, Wilmington, MA) were used for all experiments. The mice were allowed to acclimatize in the animal facility for at least 1 week prior to experimentation. Animals were randomly assigned into either a thermal injury group or a sham treatment group. The experiments in this study were approved by the Institutional Animal Care and Use Committee of the University of Texas Health Science Center at San Antonio, and were performed in accordance with the National Institutes of Health guidelines for the care and handling of laboratory animals.

\section{Thermal injury procedure}

Mice received a scald burn as described previously [9]. Briefly, the mice were anesthetized by intraperitoneal (IP) injection of ketamine/xylazine, and the dorsal surface was shaved. The anesthetized mouse was placed in a custom insulated mold exposing $12.5 \%$ of their total body surface area (TBSA) along the right dorsum. The mold was immersed in $70^{\circ} \mathrm{C}$ water for $10 \mathrm{sec}$ to produce a 3rd degree burn. The burn procedure was repeated on the left dorsum yielding a total burn size of 25\% TBSA. The mice were then resuscitated with $1 \mathrm{ml}$ of Ringer's lactate solution administered by intraperitoneal injection and returned to their cages. The cages were placed on a heating pad for $2 \mathrm{hr}$ until the mice were fully awake, at which time they were returned to the animal facility. Sham treatment consisted of anesthesia and resuscitation with Ringer's lactate solution only.

\section{Tissue collection and processing}

At $3 \mathrm{hr}$ after injury the mice were euthanized and tissue samples collected (plasma, heart, lung, liver, and small intestine). The tissue samples were snap frozen in liquid nitrogen and stored at $-80^{\circ} \mathrm{C}$ prior to analysis.

\section{Cytokine, Troponin-I, Myleoperoxidase and HMGB-1 determinations}

Tissue samples were homogenized in protease inhibitor cocktail as previously described prior to analysis [10]. Plasma samples were not treated. Tissue levels of Th-17 (IL-6, IL-17, IL-22, IL-23, TGF- $\beta$ ) Th-1 (IFN- $\gamma$ ), and Th-2 (IL-10) cytokines were determined by ELISA according to the manufacturer's recommendations $(R \& D$ Systems) Plasma cardiac specific Troponin-I, HMGB-1 levels and cardiac myleoperoxidase (MPO) levels were determined by ELISA similarly, (Genway, Shino-Test Corp, Hycult biotechnology). Values obtained were normalized to total protein of the tissue homogenate as determined by BCA assay.

\section{Statistical analysis}

Data are expressed as mean \pm SE. Comparisons were analyzed using ANOVA. A $P$ value of $<0.05$ was considered to be statistically significant for all analyses.

\section{Results}

Burn induces an increased Th-17 response in the heart at $\mathbf{3}$ hours after injury

Sham and burn groups were composed of 6 and 5 animals, respectively. There were no animal deaths after burn or sham procedures. At 3 hrs, 1 day, 3 days and 7 days after the burn or sham treatment, animals were euthanized and the heart removed. As shown in figure 1 , burn caused a significant $(P<0.05)$ elevation in the cardiac levels of IL-17, 3 hours after injury as compared to the sham animals. One day after burn, IL-17 remained elevated, however, without significant difference from the respective sham group. Sham levels of IL-17 were significantly $(\mathrm{P}<0.05)$ greater at $3 \mathrm{hrs}$ and 1 day as compared with days 3 and 7 . This early cytokine response is likely related to volume loading early after resuscitation, as both sham and burn mice received resuscitation fluid. Based on the observation that the IL-17 response was significantly higher at $3 \mathrm{hrs}$ after burn, all subsequent analysis was conducted on that group of animals.

In addition to IL-17, we analyzed the heart for the Th-17 family cytokines IL-6, IL-22, IL-23 and TGF- $\beta$. As shown in figure 2, burn induced an early myocardial inflammation as evidenced by significantly higher $(P<$ $0.05)$ levels of IL-17, IL- 6 and IL-22 in the burn group as compared to the sham animals. The TGF- $\beta$ response was not different between groups and IL-23 was virtually undetectable in cardiac tissue samples.

We also investigated the effects of burn in other tissues at 3 hrs after injury. Table 1 summarizes the findings for plasma, liver, lung and small intestine. In

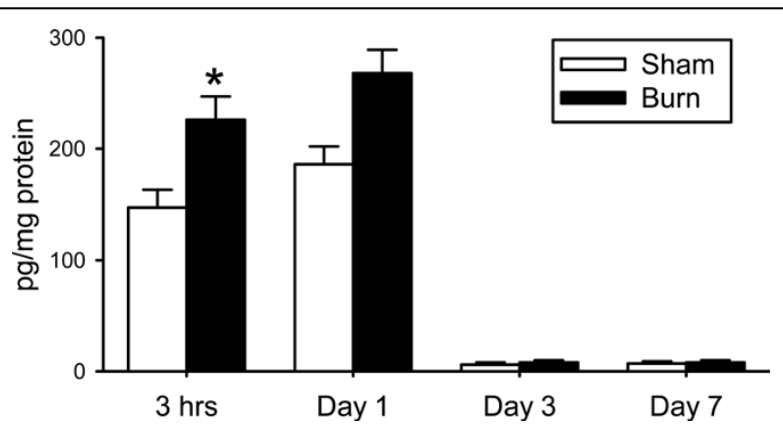

Figure 1 Cardiac IL-17: Cardiac tissue at 3 hrs, 1 day, 3 days and 7 days was assessed for IL-17 content as described in the Materials and methods. Data are mean \pm SE for 5-6 mice/group. ${ }^{*} \mathrm{P}<0.05$ as compared to sham. 


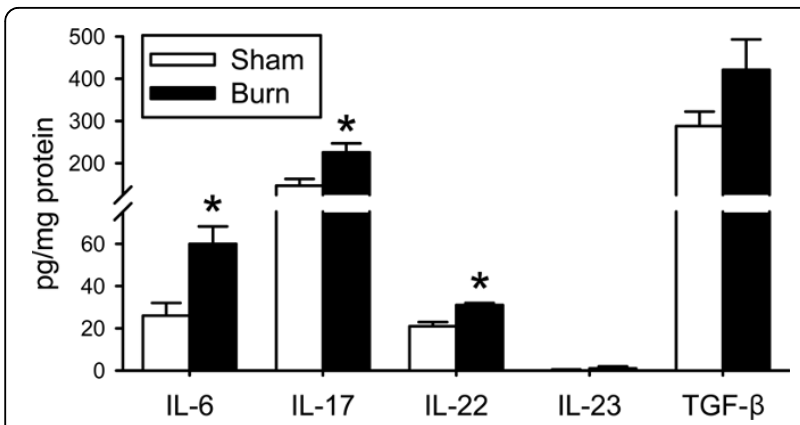

Figure 2 Cardiac Th-17 Cytokines: Cardiac tissue at 3 hrs after burn or sham procedure was assessed for content of Th-17 cytokines as described in the Materials and Methods. Data are mean \pm SE for 5-6 mice/group. Data shown for IL-17 is the same as that shown for IL-17 at 3 hrs in Fig.1 and is included for comparative purposes. *P $<0.05$ as compared to sham.

contrast to the cardiac response, no significant differences were found in those tissues with regard to IL-6, IL-17 and IL-22 levels.

\section{Burn induces heart injury at $\mathbf{3}$ hours after burn}

We found that burn was associated with increased Troponin-I levels at 3 hours after injury (Fig. 3A), indicating cardiomyocyte damage. At 24 hours after the burn, the Troponin-I levels began to normalize and did not differ from those of the uninjured animal (data not shown). Plasma levels of the early inflammatory marker HMGB-1 were not elevated at $3 \mathrm{hrs}$ (Fig 3B). To elucidate the role of neutrophils in the early cardiac injury after burn, we analyzed heart tissue for MPO levels. As shown in Fig. 3C., MPO levels were unchanged in the burn group as compared to the sham animals at 3 hours after burn. Histologic analysis indicated no major changes in cardiac morphology at $3 \mathrm{hrs}$ after burn (data not shown.)

\section{Burn induced cardiac cytokine response is Th-17 specific}

To determine whether the cytokine response in the heart after burn was also related to changes in the Th1

Table 1 Tissue levels of IL-6, IL-17 and IL-22.

\begin{tabular}{cccccc}
\hline & & Plasma & Lung & Liver & S.I. \\
\hline IL-17 & Sham & $\mathrm{n} / \mathrm{d}$ & $175 \pm 60$ & $421 \pm 96$ & $19 \pm 13$ \\
& Burn & $\mathrm{n} / \mathrm{d}$ & $133 \pm 60$ & $309 \pm 63$ & $18 \pm 14$ \\
\hline \multirow{2}{*}{$\mathrm{L}-6$} & Sham & $\mathrm{n} / \mathrm{d}$ & $72 \pm 20$ & $103 \pm 15$ & $4 \pm 3$ \\
& Burn & $\mathrm{n} / \mathrm{d}$ & $53 \pm 8$ & $70 \pm 15$ & $4 \pm 3$ \\
\hline IL-22 & Sham & $\mathrm{n} / \mathrm{d}$ & $50 \pm 17$ & $66 \pm 5$ & $6 \pm 2$ \\
& Burn & $\mathrm{n} / \mathrm{d}$ & $20 \pm 3$ & $59 \pm 7$ & $5 \pm 2$
\end{tabular}

Plasma, lung, liver and small intestine levels of IL-17, IL-6 and IL-22 were determined as described in Materials and Methods. Samples of sham and burn mice were collected 3 hrs after burn or sham procedure. Data are mean $\pm \mathrm{SE}$; $\mathrm{n}=6$ mice/group. No significant differences were found on those tissues in the burn group compared to the sham animals. $n / d=$ not detectable
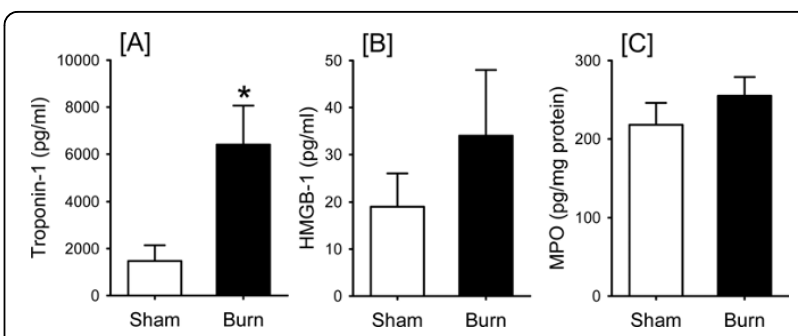

Figure 3 Cardiac MPO and plasma Troponin and HMGB-1 levels: At $3 \mathrm{hrs}$ after burn and sham, plasma Troponin (A) and plasma HMGB-1 (B) and cardiac MPO (C) levels were assessed as described in the Materials and Methods. Data are mean \pm SE for 5-6 mice/group. ${ }^{*} \mathrm{P}<0.05$ as compared to sham.

and Th2 we analyzed heart tissue for IFN- $\gamma$ or IL-10 as specific markers of the Th1 and Th2 response respectively. IFN- $\gamma$ was not detectable irrespectively of the group and IL-10 levels were similar in sham and burned animals at $3 \mathrm{hrs}$ after injury. (Table 2)

\section{Discussion}

The inflammatory cascade elicited by burn activates a broad immunoinflammatory response known as the Systemic Inflammatory Response Syndrome (SIRS). This response involves a wide range of cells (e.g, macrophages, T-cells, neutrophils) and tissues (e.g., skin, spleen, liver, cardiac, lung). Ultimately, SIRS increases the potential for the development of Multiple Organ Dysfunction Syndrome (MODS). Since the initial studies of Blalock in the 1930's about cardiovascular impairment after burn, many models have been proposed to explain its pathophysiology including fluid shift, changes in the microcirculation, coagulopathy and peripheral vasoconstriction, however, the most recent research studies have been focused on the association of certain factors with the cardiac dysfunction after burns, including complement, cellular apoptosis and cytokines as the purpose of the current study [2,11-14]. The pathophysiologic response in the cardiovascular system includes myocardial contractile dysfunction and increased vascular permeability. Several studies have shown that cardiac depression associated to burn injuries occurs independently of the plasma loss, develops early after the injury and early large volume resuscitation does not affect morbidity or mortality, suggesting an intrinsic tissue

Table 2 Cardiac levels of IFN- $\gamma$ and IL-10

\begin{tabular}{ccc}
\hline & Sham & Burn \\
\hline $\mathrm{IL}-10$ & $87 \pm 25$ & $133 \pm 28$ \\
$\mathrm{IFN}-\boldsymbol{\gamma}$ & $\mathrm{n} / \mathrm{d}$ & $\mathrm{n} / \mathrm{d}$ \\
\hline
\end{tabular}

Cardiac levels of IL-10 and IFN- $\gamma$ were determined 3 hrs after burn or sham procedure as described in the Materials and Methods. Data are mean $\pm \mathrm{SE}$; $\mathrm{n}=6$ mice/group. IFN- $\gamma$ was not detectable irrespectively of the group and IL-10 levels were similar in sham and burn mice. $\mathrm{n} / \mathrm{d}=$ not detectable. 
damage as a cause of its failure $[2,15,16]$. Studies have confirmed the cardiovascular function impairment is in part a consequence of increased generation of potentially harmful mediators such as pro-inflammatory cytokines in models of myocardial ischemia, burn and sepsis $[17,18]$. Studies done by Barber et al, have pointed to cardiomyocytes as the source of those cytokines [3]. This study by Barber et al. also showed a correlation of the burn size and the cytokine response and the degree of left ventricular dysfunction to a nadir of $40 \%$ TBSA. Maass et al. showed a synergistic effect of IL-1 $\beta$, Il- 6 and TNF- $\alpha$ exacerbating cardiac contraction and relaxation deficits produced by any one inflammatory cytokine [17].

Studies by Finnerty et al. have recently shown that circulating IL-17 levels are increased early after burn in pediatric patients, as well in a mouse burn model $[19,20]$. These initial findings are suggestive that IL-17 plays an important role in the inflammatory response after burn. In that regard, results from the present study demonstrate that the early cardiac inflammatory response after burn involves IL-17 and other Th-17 cytokines (IL-6, IL-22). This cardiac Th-17 response correlated with the development of cardiac injury, as reflected in elevated plasma levels of Troponin-I, a sensitive and specific marker of myocardial injury after burn, correlating with cardiac contraction and relaxation deficits [21]. Huang et al. also showed a significant increase in serum levels of Troponin-I at 3 hours after burn [15]. Somewhat surprisingly elevated levels of cardiac IL-17 were observed in sham animals at 3 and 6 hrs. This apparently aberrant response may be related to volume loading due to the administration of $1 \mathrm{ml}$ IP of Ringer's lactate to the sham mice. This concept is supported by the observation that by 1 day once fluid levels have normalized IL-17 levels are barely detectable in the sham mice. In our study, the Th-17 response at $3 \mathrm{hr}$ was organ specific as other tissues (lung, liver and small intestine) did not show a significant change in the Th17 response. This does not preclude the possibility that other tissues express a Th-17 response later after injury. The recruitment of immune cells, particularly neutrophils, to a site of injury is the initial step in most inflammatory processes. Activated neutrophils release proteases and reactive oxygen intermediates, which can lead to significant tissue damage [22]. Recent studies by Abdel-Rahman showed that limiting neutrophils activity after cardiopulmonary bypass, improves perioperative hemodynamics and cardiac function, demonstrating its detrimental effects upon activation [23]. We have shown that the cardiac Th-17 response at $3 \mathrm{hr}$. post-burn is not associated with neutrophils infiltration as evidenced with unchanged levels of cardiac tissue MPO. A change in circulating levels of the HMGB-1 was also not evident in the current study. This may be in part related to the early time after injury that was investigated or the severity of the burn.

Evidence points to IL-17 as the major effector molecule produced by Th-17 cells. IL-17 stimulates several cell types, such as endothelial cells, epithelial cells and macrophages to produce multiple pro-inflammatory mediators, including IL-6 and IL-23 [24]. It also stimulates the mobilization and de novo generation of neutrophils by granulocyte-colony stimulating factor (G-CSF), thereby bridging a gap between innate and adaptive immunity and might constitute an early defense mechanism against severe sepsis [25]. Th-17-driven effector functions may also be different in different tissues [7]. We found that cardiac Th cytokine responses after burn were specific for Th-17, as cardiac levels of Th-1 (IFN- $\gamma$ ) and Th-2 (IL-10) cytokines were not significantly affected by burn. IL-17 is thought of as a T-cell derived cytokine, however, limited studies suggest to non T-cell cell types can also produce this cytokine. Recent study by Lapara NJ 3rd et al. showed that macrophages are the key source of inflammatory mediators in Leishmania infection [26]. Studies have also shown increased IL-17-expressing macrophages in active inflammatory bowel disease, high expression of IL-17 in macrophages-mediated inflammatory response in breast cancer as a promoter of invasiveness, and increased production in astrocytes and oligodendrocytes in patients with active multiple sclerosis [27-29]. Thus, the concept that cardiomyocytes can produce IL-17 directly is plausible. Future studies will need to examine the ability of isolated cardiomyocytes to produce IL-17 in vitro to validate this concept.

\section{Conclusion}

Interventions in the complex inflammatory cascade following burn might improve morbidity and mortality in this patient population. These initial findings suggest that IL-17 may provide a unique target of therapeutic intervention to reduce cardiac dysfunction after burn.

\section{Abbreviations \\ IL: interleukin; TBSA: total body surface area; TGF- $\beta$ : Transforming growth factor-Beta; IFN- $\gamma$ : Interferon gamma; TNF- $\alpha$ : tumor necrosis factor alpha; HMGB-1: High-mobility group box-1; MPO: myleoperoxidase; SIRS: Systemic Inflammatory Response syndrome; MODS: Multiple Organ Dysfunction Syndrome.}

\section{Acknowledgements}

We appreciated the excellent technical assistance of Ebony Cavanaugh in the experiments. Support was provided by National Institutes of Health grant GM079122.

\section{Authors' contributions}

JS and QZ were responsible for the animal experiments and ELISAs. MR was responsible for ELISA analysis, data analysis and scientific interpretation. RO was responsible for the data analysis, scientific interpretation and drafted the 
manuscript. MS was responsible for scientific conception, design and helped to draft the manuscript. All authors read and approved the final manuscript.

\section{Competing interests}

The authors declare that they have no competing interests.

Received: 3 May 2010 Accepted: 27 July 2010 Published: 27 July 2010

\section{References}

1. Pereira CT, Barrow RE, Sterns AM, Hawkins HK, Kimbrough CW, Jeschke MG, Lee JO, Sanford AP, Herndon DN: Age-dependent differences in survival after severe burns: a unicentric review of 1,674 patients and 179 autopsies over 15 years. J Am Coll Surg 2006, 202(3):536-548.

2. Horton JW: Left ventricular contractile dysfunction as a complication of thermal injury. Shock 2004, 22(6):495-507.

3. Barber RC, Maass DL, White DJ, Horton JW: Increasing percent burn is correlated with increasing inflammation in an adult rodent model. Shock 2008, 30(4):388-393.

4. Gauglitz GG, Song J, Herndon DN, Finnerty CC, Boehning D, Barral JM Jeschke MG: Characterization of the inflammatory response during acute and post-acute phases after severe burn. Shock 2008, 30(5):503-507.

5. Horton JW, Sanders B, White DJ, Maass DL: The effects of early excision and grafting on myocardial inflammation and function after burn injury. J Trauma 2006, 61(5):1069-1077.

6. Schwacha MG: Macrophages and post-burn immune dysfunction. Burns 2003, 29(1):1-14

7. Korn T, Bettelli E, Oukka M, Kuchroo VK: IL-17 and Th17 Cells. Annu Rev Immunol 2009, 27:485-517.

8. Awasthi A, Kuchroo VK: Th17 cells: from precursors to players in inflammation and infection. Int Immunol 2009, 21(5):489-498

9. Alexander M, Chaudry IH, Schwacha MG: Relationships between burn size, immunosuppression, and macrophage hyperactivity in a murine model of thermal injury. Cell Immunol 2002, 220(1):63-69.

10. Faunce DE, Llanas JN, Patel PJ, Gregory MS, Duffner LA, Kovacs EJ: Neutrophil chemokine production in the skin following scald injury. Burns 1999, 25(5):403-410.

11. Carlson DL, Horton JW: Cardiac molecular signaling after burn trauma. J Burn Care Res 2006, 27(5):669-675.

12. Hoesel LM, Niederbichler AD, Schaefer J, Ipaktchi KR, Gao H, Rittirsch D, Pianko MJ, Vogt PM, Sarma JV, Su GL, Arbabi S, Westfall MV, Wang SC, Hemmila MR, Ward PA: C5a-blockade improves burn-induced cardiac dysfunction. J Immunol 2007, 178(12):7902-7910.

13. Zhang JP, Ying $X$, Liang WY, Luo ZH, Yang ZC, Huang YS, Wang WC: Apoptosis in cardiac myocytes during the early stage after severe burn. J Trauma 2008, 65(2):401-408.

14. Wang L, Quan J, Johnston WE, Maass DL, Horton JW, Thomas JA, Tao W: Age-dependent differences of interleukin-6 activity in cardiac function after burn complicated by sepsis. Burns 2009, 36(2):232-238.

15. Huang YS, Yang ZC, Yan BG, Yang JM, Chen FM, Crowther RS, Li A: Pathogenesis of early cardiac myocyte damage after severe burns. J Trauma 1999, 46(3):428-432

16. Chung KK, Wolf SE, Cancio LC, Alvarado R, Jones JA, McCorcle J, King BT, Barillo DJ, Renz EM, Blackbourne LH: Resuscitation of severely burned military casualties: fluid begets more fluid. J Trauma 2009, 67(2):231-237.

17. Maass DL, White J, Horton JW: IL-1 beta and IL-6 act synergistically with TNF-alpha to alter cardiac contractile function after burn trauma. Shock 2002, 18(4):360-366.

18. Cha J, Wang Z, Ao L, Zou N, Dinarello CA, Banerjee A, Fullerton DA Meng $X$ : Cytokines link Toll-like receptor 4 signaling to cardiac dysfunction after global myocardial ischemia. Ann Thorac Surg 2008, 85(5):1678-1685.

19. Finnerty CC, Herndon DN, Przkora R, Pereira CT, Oliveira HM, Queiroz DM, Rocha AM, Jeschke MG: Cytokine expression profile over time in severely burned pediatric patients. Shoc 2006, 26(1):13-19.

20. Finnerty CC, Przkora R, Herndon DN, Jeschke MG: Cytokine expression profile over time in burned mice. Cytokine 2009, 45(1):20-25.

21. Murphy JT, Horton JW, Purdue GF, Hunt JL: Evaluation of troponin-I as an indicator of cardiac dysfunction after thermal injury. J Trauma 1998, 45(4):700-704

22. Moore K: Cell biology of chronic wounds: the role of inflammation. J Wound Care 1999, 8(7):345-348.
23. Abdel-Rahman U, Margraf S, Aybek T, Lögters T, Bitu-Moreno J, Francischetti I, Kranert T, Grünwald F, Windolf J, Moritz A, Scholz M: Inhibition of neutrophil activity improves cardiac function after cardiopulmonary bypass. J Inflamm 2007, 10(4):21.

24. Spolski R, Leonard WJ: Cytokine mediators of Th17 function. Eur J Immunol 2009, 39(3):658-661.

25. Kasten KR, Tschöp J, Adediran SG, Hildeman DA, Caldwell CC: T Cells are potent early mediators of the host response to sepsis. Shock.

26. Lapara NJ, Kelly BL: Suppression of LPS-induced inflammatory responses in macrophages infected with Leishmania. J Inflamm (Lond) 2010, 2;7(1):8.

27. Fujino S, Andoh A, Bamba S, Ogawa A, Hata K, Araki Y, Bamba T, Fujiyama Y: Increased expression of interleukin 17 in inflammatory bowel disease. Gut 2003, 52(1):65-70.

28. Zhu X, Mulcahy LA, Mohammed RA, Lee AH, Franks HA, Kilpatrick L, Yilmazer A, Paish EC, Ellis IO, Patel PM, Jackson AM: IL-17 expression by breast-cancer-associated macrophages: IL-17 promotes invasiveness of breast cancer cell lines. Breast Cancer Res 2008, 10(6):R95.

29. Tzartos JS, Friese MA, Craner MJ, Palace J, Newcombe J, Esiri MM, Fugger L: Interleukin-17 production in central nervous system-infiltrating T cells and glial cells is associated with active disease in multiple sclerosis. Am J Pathol 2008, 172(1):146-155.

doi:10.1186/1476-9255-7-38

Cite this article as: Oppeltz et al:: Increased expression of cardiac IL-17 after burn. Journal of Inflammation 2010 7:38.

\section{Submit your next manuscript to BioMed Central and take full advantage of:}

- Convenient online submission

- Thorough peer review

- No space constraints or color figure charges

- Immediate publication on acceptance

- Inclusion in PubMed, CAS, Scopus and Google Scholar

- Research which is freely available for redistribution 